\title{
Nghiên cứu quy trình chiết xuất và tinh chế Rotudin từ củ bình vôi (Stephania rotunda Lour.) trồng tại tỉnh Hòa Bình
}

\section{The procedure for extracting and purifying Rotudin from tubers of (Stephania rotunda Lour.) grown in Hoa Binh province}

\author{
Nguyễn Minh Hoàng $^{1 *}$, Tôn Nữ Yên Quỳnh ${ }^{1}$ \\ ${ }^{1}$ Trường Đại học Mở Thành phố Hồ Chí Minh, Việt Nam \\ *Tác giả liên hệ, Email: hoang.nm@ ou.edu.vn
}

THÔNG TIN

DOI:10.46223/HCMCOUJS. tech.vi.14.1.439.2019

Ngày nhận: 10/06/2019

Ngày nhận lại: 15/07/2019

Duyệt đăng: 15/07/2019

Tù khóa:

chiết xuất, 1-

tetrahydropalmatine, NMR, rotudin, Stephania rotunda

Keywords:

extraction; 1-

tetrahydropalmatine, NMR data, rotudin, Stephania rotunda

\section{TÓM TÁT}

Củ bình vôi (Stephania rotunda Lour.) trồng tại tỉnh Hòa Bình được sử dụng làm nguyên liệu để chiết xuất 1-tetrahydropalmatine (tên hoạt chất thuốc là Rotundin) $\mathrm{C}_{21} \mathrm{H}_{25} \mathrm{NO}_{4}$ - một alkaloid có tác dụng an thần, gây ngủ, giảm mất trí nhớ. Mục đích của nghiên cứu là tìm ra một quy trình chiết xuất rotudin đơn giản, rẻ tiền, hiệu quả để có thể ứng dụng. Kết quả thu được cho thấy:

- Phương pháp ngâm chiết với tỉ lệ $1 / 6$ giữa bột khô củ bình vôi và thể tích dung dịch $\mathrm{H}_{2} \mathrm{SO}_{4} 1 \%$ cho hiệu suất trích ly cao nhất 0,35\%. Hợp chất thu được đạt độ tinh khiết 98\% (trên HPLC);

- Cấu trúc hóa học được xác nhận trên phổ NMR.

ABSTRACT
Tubers of Stephania rotunda Lour. grown in Hoa Binh
province are used as raw materials for extracting 1-
tetrahydropalmatine (a medical jargon-Rotundin) $\mathrm{C}_{21} \mathrm{H}_{25} \mathrm{NO}_{4}-\mathrm{a}$
major component - alkaloid with the effects of sedative and
preventing loss of memory. The purpose of this research is to
study a simple, inexpensive, and efficient procedure for extracting
rotudin.
$\quad-\mathrm{Maceration}$ method of $1 / 6$ of dried powder of tubers with $_{1 \% \mathrm{H}_{2} \mathrm{SO}_{4} \text { solution gives the highest yield of } 0.35 \% \text { on the }}$
extraction. The purity of rotudin is $98 \%$ on HPLC.
$\quad-$ The chemical structure of rotudin was confirmed by NMR
data.

\section{1. Đặt vấn đề}

Những năm gần đây, cùng với sự tiến bộ của y học, các loại thuốc an thần, chống mất ngủ là một trong những sản phẩm được quan tâm nghiên cứu. Thực tế, phần lớn các loại thuốc an thần phổ biến trên thị trường hiện nay đều có nguồn gốc từ con đường tổng hợp hóa dược và nhập khẩu. Tuy nhiên, các loại thuốc này lại gây ra một số tác dụng phụ nếu sử dụng trong thời gian dài nên việc xây dựng quy trình sản xuất thuốc từ thảo dược thiên nhiên đang được quan tâm. 
Củ bình vôi có tên khoa học là Stephania rotunda Lour. thuộc họ Tiết dê (Menisspermaceae) là một loại cây dây leo chủ yếu phân bố ở Trung Quốc và các nước Đông Nam Á như Việt Nam. Củ bình vôi chứa các alkaloid khác nhau, trong đó hợp chất rotundin (hay L-tetrahydropalmatin) chiếm hàm lượng lớn. Trong y học cổ truyền từ xưa, củ bình vôi đã được dùng dưới dạng thuốc sắc hay ngâm rượu chữa mất ngủ, an thần, nhức đầu, đau bụng, ... Hiện nay rotundin được dùng chủ yếu để chữa bệnh mất ngủ và an thần. Rotundin nguồn gốc tự nhiên có những ưu điểm nổi bật như độc tính thấp, sự dung nạp thuốc tốt, mang lại giấc ngủ sinh lý, giúp hồi phục trí nhớ (L. T. Do, 2004; Hung et al., 2010; Semwal et al., 2010; Thuy, Franke, Porzel, Wessjohann, \& Sung, 2006).

Nguồn dược liệu củ bình vôi ở nước ta khá phong phú. Do đó, việc nghiên cứu, xây dựng được một quy trình chiết xuất rotudin từ củ bình vôi đạt hiệu quả cao, có khả năng ứng dụng trong công nghiệp để tận dụng nguồn dược liệu phong phú trong nước là công việc rất có ý nghĩa.

\section{Vật liệu và phương pháp nghiên cứu}

Bài báo này trình bày kết quả nghiên cứu quy trình chiết xuất và tinh chế rotudin trích từ củ bình vôi (Stephania rotunda Lour.) trồng tại tỉnh Hòa Bình bằng dung môi acid $\mathrm{H}_{2} \mathrm{SO}_{4}$ $1 \%$. Cấu trúc của rotudin được xác định bằng khối phổ $(\mathrm{MS})$ và phổ cộng hưởng từ hạt nhân (NMR).

\section{Nguyên liệu}

Củ bình vôi (Stephania rotunda Lour.) tươi được thu hái tại địa bàn xã Sủ Ngòi, thành phố Hòa Bình, tỉnh Hòa Bình vào tháng 10 năm 2017. Mẫu được giám định tên khoa học dựa vào đặc điểm hình thái mô tả trong các tài liệu về thực vật và dược điển (Bộ Y tế, 2009; $\mathrm{B}$. H. Do, 2004; L. T. Do, 2004). Sau khi thu hái, nguyên liệu được rửa sạch để loại bỏ bụi đất, cắt bỏ

phần hư; để ráo nước và cắt thành lát mỏng đem sấy khô, xay nhỏ rồi bảo quản ở nhiệt độ phòng trong túi nilon kín.

\section{Phương pháp nghiên cứu}

Rotudin thô được chiết bằng dung dịch $\mathrm{H}_{2} \mathrm{SO}_{4} 3 \%$ như mô tả trong tài liệu (Le et al., 2014), có bổ sung cho phù hợp với thực tế (Hình 1).

Phương pháp sắc ký với chất hấp phụ là silica gel được sử dụng để cô lập rotudin tinh khiết. 
Quy trình chiết xuất chung rotudin và các alkaloid

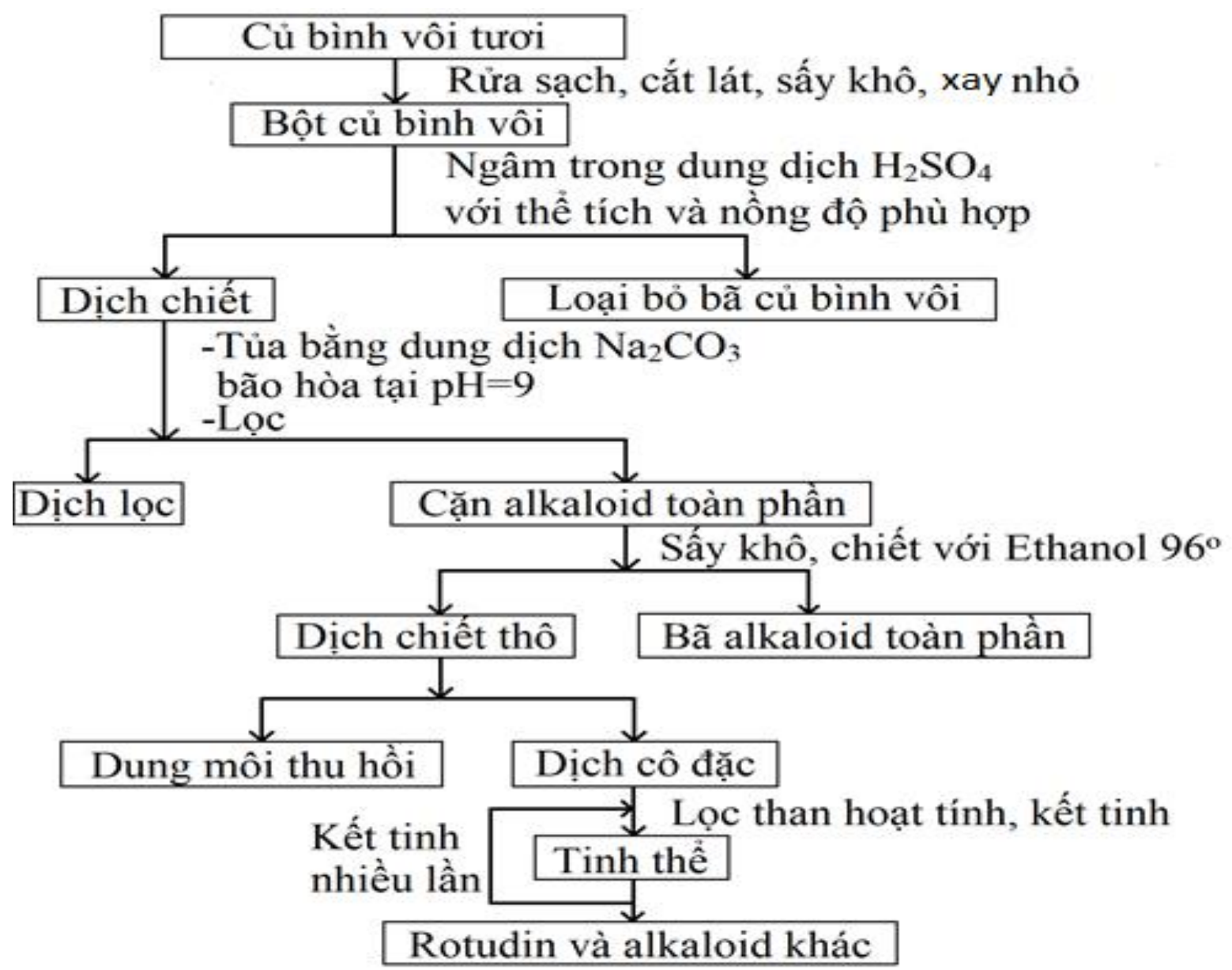

Hình 1. Sơ đồ tóm tắt quy trình chung chiết xuất rotudin và các alkaloid khác

Thực nghiệm

Bước 1: Chuẩn bị nguyên liệu và chiết alkaloid toàn phần

Củ bình vôi được rửa sạch, để ráo nước, cắt thành lát mỏng rồi đem sấy ở $60^{\circ} \mathrm{C}$ cho đến khi khô cứng, sau đó xay thành bột. Cân chính xác $50 \mathrm{~g}$ bột củ bình vôi đã sấy khô vào ngâm trong dung dịch $\mathrm{H}_{2} \mathrm{SO}_{4}$ với thể tích và nồng độ phù hợp (Khảo sát các yếu tố ảnh hưởng đến hiệu suất chiết xuất rotudin thô). Thời gian ngâm chiết mỗi lần là 24 giờ.

Lọc lấy dịch chiết alkaloid. Chiết thêm hai lần. Gộp các dịch chiết đã lọc với nhau rồi kiềm hóa bằng dung dịch $\mathrm{Na}_{2} \mathrm{CO}_{3}$ bão hòa đến $\mathrm{pH}=9$ (thay cho việc dùng $\mathrm{NaOH} 10 \%$ của Le và cộng sự (2014)). Lọc lấy tủa alkaloid toàn phần và đem sấy khô ở nhiệt độ $60^{\circ} \mathrm{C}$.

Bước 2: Tinh chế rotudin và các alkaloid khác

Tủa (cặn) alkaloid toàn phần thu được đem nghiền thành bột mịn, chiết với ethanol $96^{\circ}$ bằng phương pháp đun khuấy từ ở nhiệt độ $80^{\circ} \mathrm{C}$ trong 4 giờ rồi lọc. Gộp các dịch chiết và thu 
hồi dung môi, thu được hỗn hợp dịch rotudin thô và các alkaloid khác. Hỗn hợp dịch rotudin thô được tẩy màu bằng than hoạt tính. Dịch lọc được để yên $2-3$ ngày ở nhiệt độ phòng để kết tinh. lại.

Lọc lấy tinh thể bằng phễu Buchner, rửa bằng ethanol $96^{\circ}$ để loại bỏ các tạp chất còn

\section{Khảo sát các yếu tố ảnh hưởng đến hiệu suất chiết xuất rotudin thô}

Thí nghiệm 1: Khảo sát tỉ lệ thể tích dung dịch $\mathrm{H}_{2} \mathrm{SO}_{4}$ ngâm chiết tối ưu

Cân chính xác $50 \mathrm{~g}$ bột củ bình vôi đã sấy khô. Tiến hành ngâm chiết nguyên liệu trong dung dịch $\mathrm{H}_{2} \mathrm{SO}_{4}(3 \%)$ với tỉ lệ bột nguyên liệu và thể tích dung dịch tăng dần 1/4, 1/5, 1/6, $1 / 7$. Ở mỗi nghiệm thức thực hiện chiết 3 lần để chiết kiệt các alkaloid. Dịch chiết thu được ở mỗi nghiệm thức tiếp tục được đem đi tinh chế theo quy trình chung. Sản phẩm được cân tính hiệu suất và kiểm tra độ tinh khiết bằng sắc ký bản mỏng. Tỉ lệ thể tích dung dịch $\mathrm{H}_{2} \mathrm{SO}_{4}$ tối ưu sẽ được sử dụng cho các thí nghiệm khảo sát tiếp theo.

Thí nghiệm 2: Khảo sát nồng độ dung dịch acid sulfuric ngâm chiết tối ưu

Bột củ bình vôi được đem đi ngâm chiết theo các nồng độ khác nhau: $0,5 \%, 1 \%, 2 \%$ và $3 \%$. Dịch chiết sau khi lọc được kiềm hóa với dung dịch $\mathrm{Na}_{2} \mathrm{CO}_{3}$ bão hòa, rồi tiến hành thu tủa như quy trình chung.

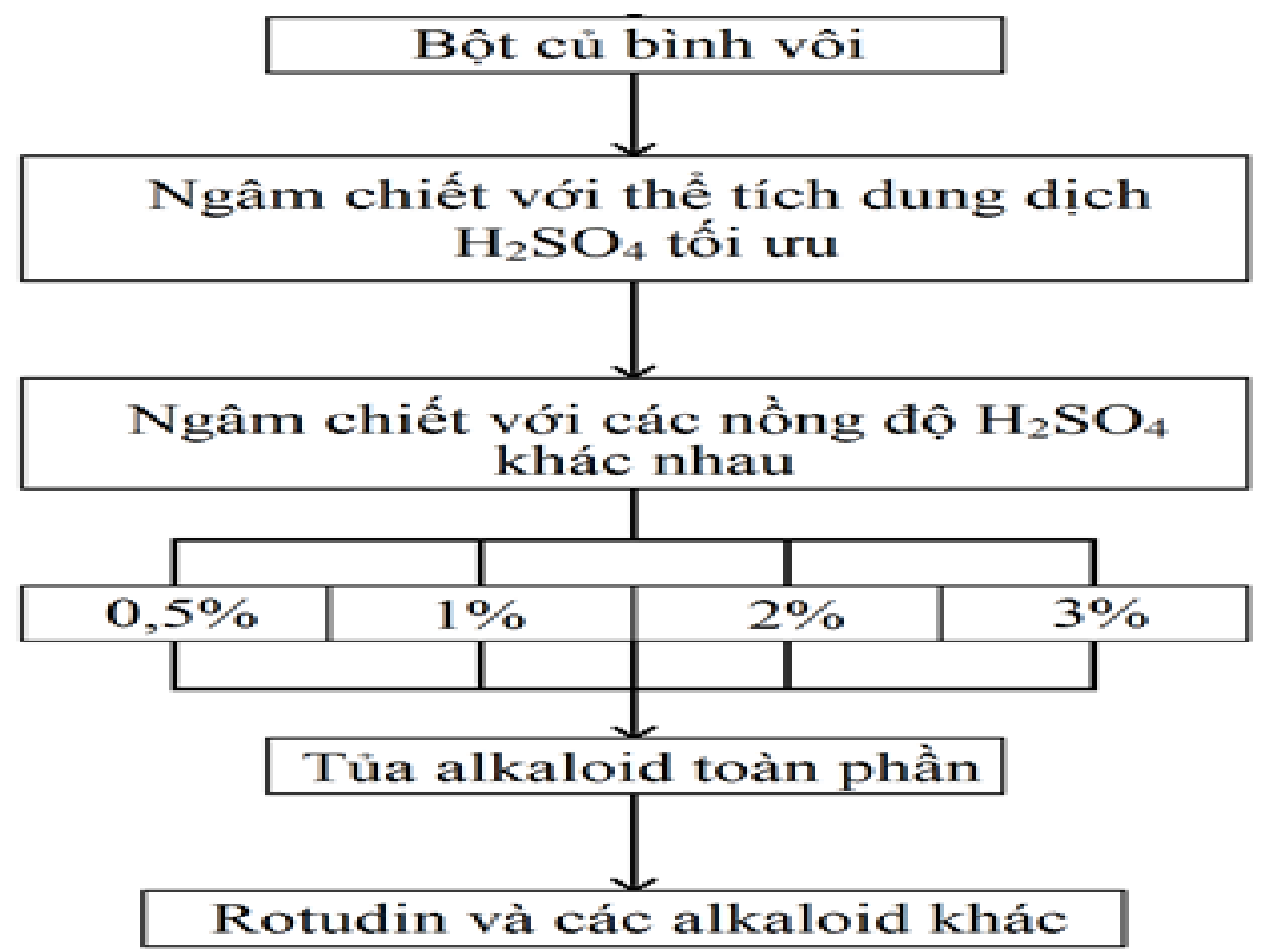


Bước 3: Cô lập thành phần rotudin bằng phuơng pháp sắc ký cột

Pha động: hệ dung môi giải ly là chloroform: ethanol (99:1 đến 10:90).

Pha tĩnh: silica gel cỡ hạt 0,063 - 0,200mm (Merck).

Khối lượng mẫu $1 \mathrm{~g}$. thể tích mỗi phân đoạn $10 \mathrm{ml}$. Pha động là hệ dung môi chloroform: ethanol (tỉ lệ 99:1 tới 0:100). Vận tốc giải ly $1 \mathrm{ml} / 2$ phút. Các phân đoạn giống nhau trên TLC được gộp lại. Phân đoạn II dùng hệ chloroform:ethanol (70:30) chỉ có một vết trên TLC, được đặt tên là RO1.

Bước 4: Nhận danh và xác định cấu trúc hợp chất thu được

- Phương pháp HPLC-MS: được thực hiện trên máy Thermo Scientific MSQ Plus tại Trung tâm nghiên cứu ứng dụng, Viện Hàn lâm khoa học \& công nghệ Việt Nam;

- Phương pháp phổ cộng hưởng từ hạt nhân NMR: kết quả phân tích được đo trên máy Bruker Avance III 500MHz tại Viện Hóa học thuộc Viện Hàn lâm khoa học \& công nghệ Việt Nam.

\section{Kết quả và thảo luận}

Kết quả khảo sát tỉ lệ thể tích dung dịch $\mathrm{H}_{2} \mathrm{SO}_{4}$ ngâm chiết tối ưu

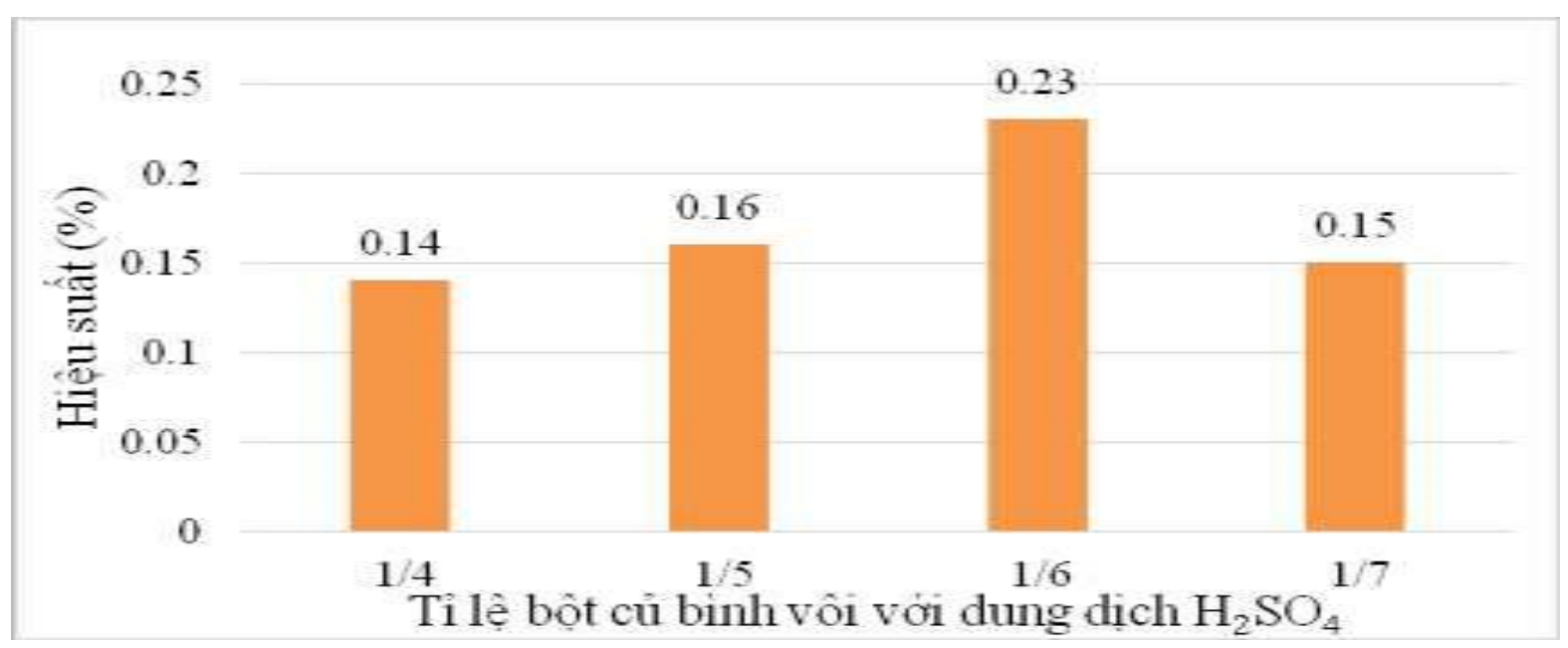

Hình 2. Đồ thị biểu diễn hiệu suất chiết rotudin thô theo các tỉ lệ ngâm chiết khác nhau

Qua quá trình khảo sát cho thấy tỉ lệ $1 / 6$ giữa bột bình vôi và thể tích dung dịch $\mathrm{H}_{2} \mathrm{SO}_{4}$ phù hợp để chiết thô rotudin do đạt hiệu suất cao $(0,23 \%)$. Trong dịch kết tinh không thấy xuất hiện nhựa dầu. Bên cạnh đó, thời gian tạo thành tinh thể khi ngâm chiết theo tỉ lệ 1/6 nhanh hơn so với các tỉ lệ khác.

\section{Kết quả khảo sát nồng độ dung dịch $\mathrm{H}_{2} \mathrm{SO}_{4}$ ngâm chiết tối uu}

Thực hiện chiết rotudin thô trong dung dịch acid sulfuric với các nồng độ khác nhau theo tỉ lệ $1 / 6$ của thí nghiệm trước. Qua quá trình khảo sát, hiệu suất chiết trong dung dịch $\mathrm{H}_{2} \mathrm{SO}_{4} 1 \%$ là cao nhất $(0,35 \%)$. 


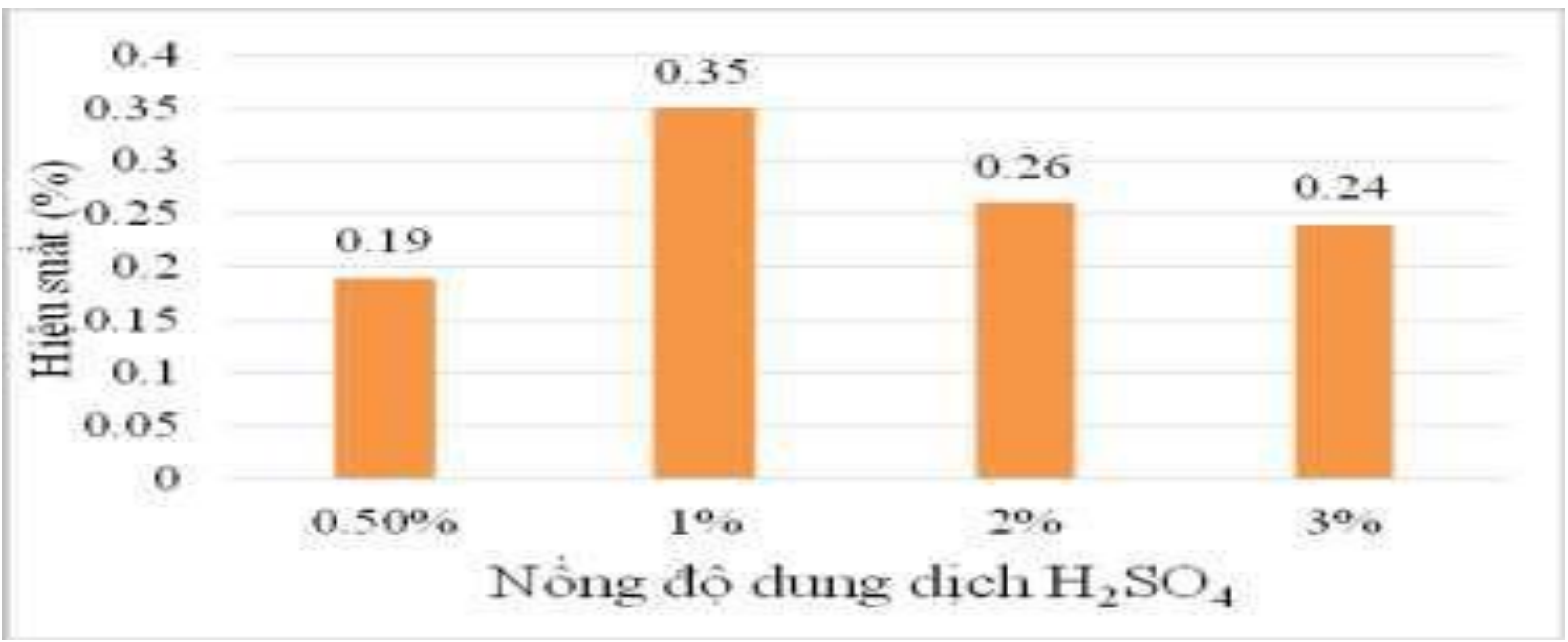

Hình 3. Đồ thị biểu diễn hiệu suất chiết rotudin thô theo các nồng độ $\mathrm{H}_{2} \mathrm{SO}_{4}$ khác nhau

Kết quả: bột bình vôi ngâm chiết trong dung dịch $\mathrm{H}_{2} \mathrm{SO}_{4} 1 \%$ với tỉ lệ thể tích $1 / 6$ là tối ưu nhất. Kết quả này có sự khác biệt so với Le và cộng sự (2014) cho thấy nồng độ $\mathrm{H}_{2} \mathrm{SO}_{4}$ tối ưu là 3-4\% có thể do tác giả thực hiện trên mẫu củ bình vôi tươi nên cần nồng độ lớn mới chiết được.

\section{Kết quả định tính rotudin và các alkaloid khác}

Tinh thể thu được sau khi thực hiện các khảo sát ngâm chiết sẽ được đánh giá độ tinh khiết sơ bộ bằng các phương pháp sắc ký bản mỏng, đo điểm nóng chảy và HPLC-MS.

Kết quả sắc ký bản mỏng (Hình 6) cho thấy có một vệt đậm cao tương đương chất chuẩn rotudin với $\mathrm{Rf}=0,48$, cho thấy đây có thể là rotudin.

\section{Kết quả đo điểm nóng chảy}

Kết quả đo điểm nóng chảy cho thấy nhiệt độ nóng chảy của chất chiết $\left(141^{\circ} \mathrm{C}\right)$ gần với nhiệt độ nóng chảy của rotudin chuẩn $\left(142^{\circ} \mathrm{C}\right)$ và tài liệu tham khảo (Blanchfield, Sands, Kennard, Byriel, \& Kitching, 2003).

\section{Kết quả sắc ký lỏng hiệu năng cao ghép đầu dò khối phổ (HPLC-MS)}

Lấy mẫu đã khảo sát tỉ lệ thể tích và nồng độ dung dịch $\mathrm{H}_{2} \mathrm{SO}_{4}$ tối ưu cho quá trình ngâm chiết đi kiểm tra độ tinh khiết bằng phương pháp HPLC-MS.

Tại thời gian lưu 7,689 phút xuất hiện một mũi cao nhất có độ tinh khiết là 98,875\%. Ngoài ra, tại thời gian lưu 5,281 phút và 6,405 phút xuất hiện hai mũi nhỏ có hàm lượng lần lượt là $0,876 \%$ và $0,249 \%$. 


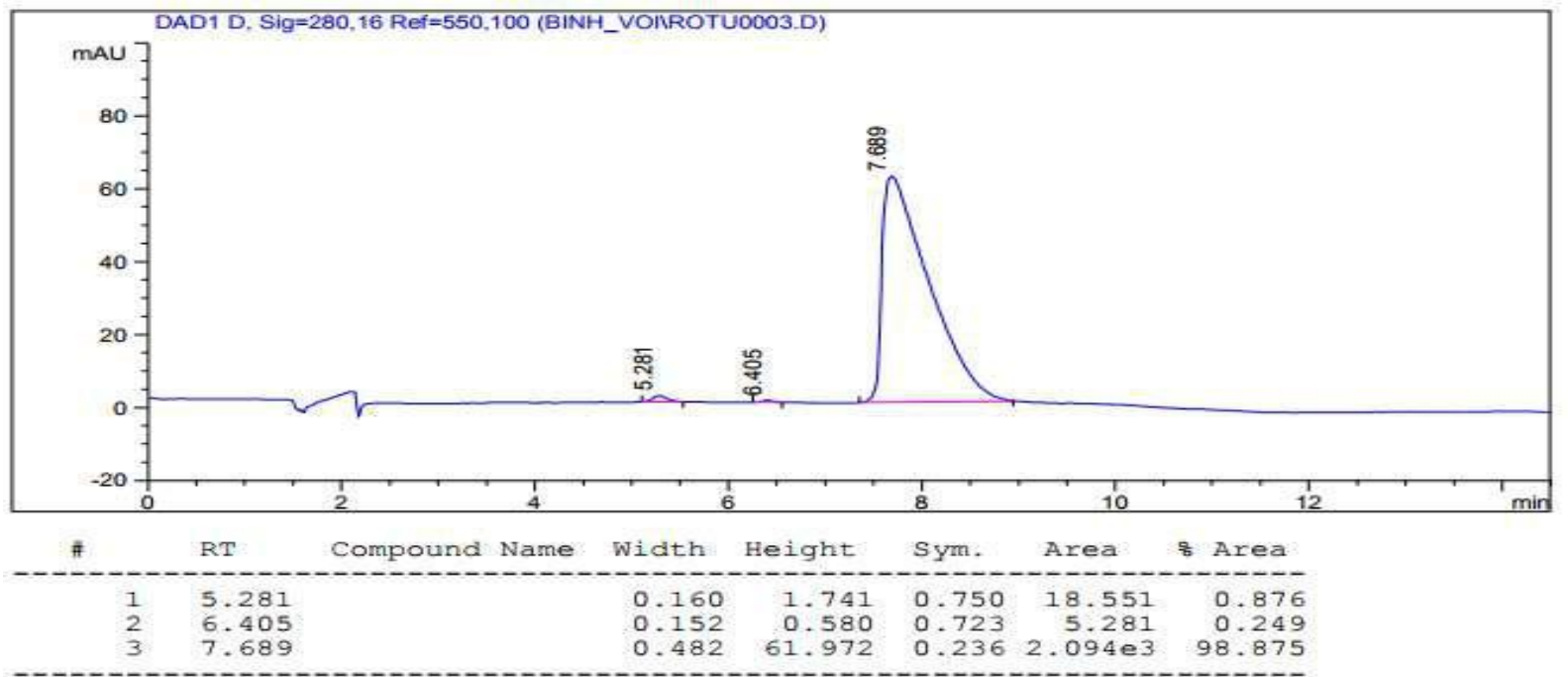

Hình 4. Kết quả sắc kí lỏng hiệu năng cao (HPLC)

Sau khi chạy khối phổ (MS) chất có thời gian lưu 7,689 phút, kết quả cho thấy có một mũi ion phân tử là $355,3 \mathrm{~m} / \mathrm{z}$ tương đương với công thức phân tử của rotudin $\mathrm{C}_{21} \mathrm{H}_{25} \mathrm{O}_{4} \mathrm{~N}$.

Như vậy, với các kết quả từ đo điểm nóng chảy, sắc kí bản mỏng, LC-MS có thể bước đầu nhận định rằng sản phẩm thu được sau quá trình chiết là rotudin.

\section{Định danh hợp chất RO1 cô lập được} bảng.

Phổ ${ }^{13} \mathrm{C}-\mathrm{NMR}$ và ${ }^{1} \mathrm{H}-\mathrm{NMR}$ của hợp chất $\mathrm{RO} 1$ trong dung môi $\mathrm{CDCl}_{3}$ cho số liệu trong

Phổ ${ }^{1} \mathrm{H}-\mathrm{NMR}$ chỉ ra sự có mặt của 4 nhóm methyl singlet ở 3,88; 3,85; 3 ,86 và 3,84ppm là 4 nhóm - $\mathrm{OCH}_{3}$ gắn ở $\mathrm{C}_{2}, \mathrm{C}_{3}, \mathrm{C}_{9}, \mathrm{C}_{10}$. Tổng số nguyên tử hidro trên phổ ${ }^{1} \mathrm{H}-\mathrm{NMR}$ là 25 . Phổ ${ }^{1} \mathrm{H}-\mathrm{NMR}$ cũng cho thấy 2 mũi singlet của 2 proton gắn ở $\mathrm{C}_{1}$ và $\mathrm{C}_{4}$ lần lượt là $6,74 \mathrm{ppm}(1 \mathrm{H}, \mathrm{s})$ và $6,62 \mathrm{ppm}(1 \mathrm{H}, \mathrm{s})$.

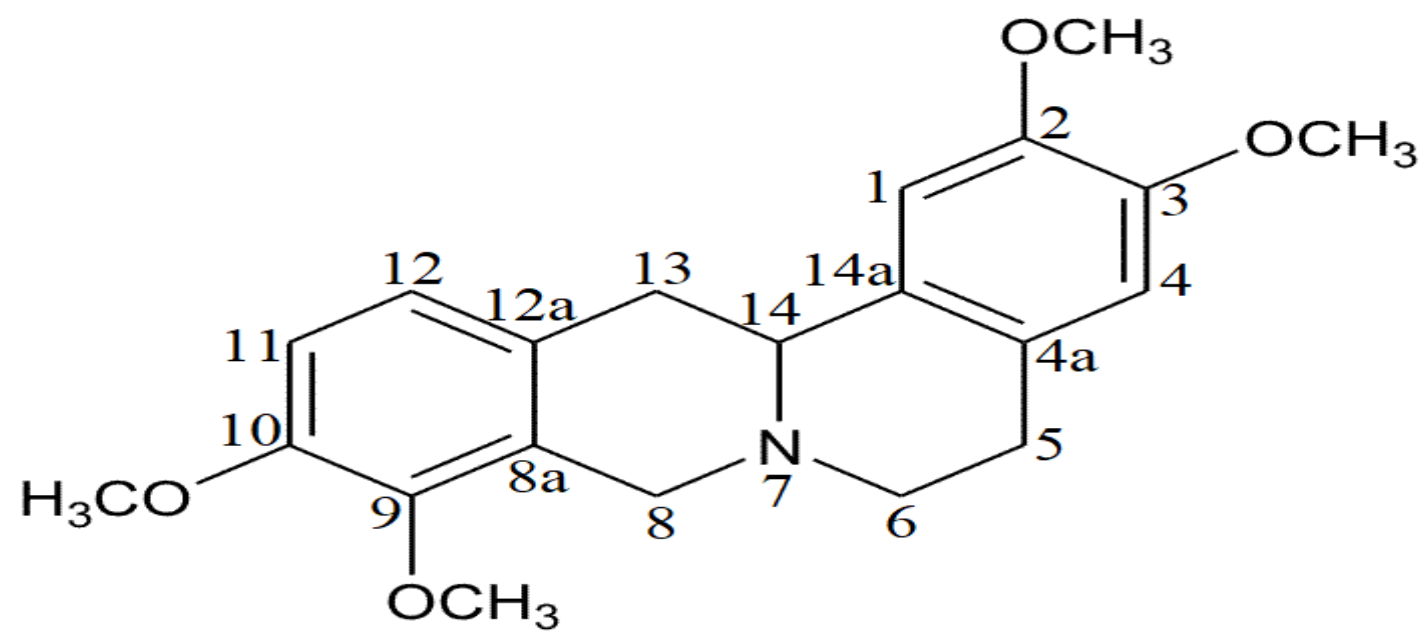

Hình 5. Cấu trúc hóa học của chất RO1 - rotudin 
Proton ở $\mathrm{C}_{11}(6,77 \mathrm{ppm})$ chẻ đôi với proton ở $\mathrm{C}_{12}(6,86 \mathrm{ppm})$ với hằng số ghép ${ }^{3} \mathrm{~J}$ là $8,5 \mathrm{~Hz}$, do 2 proton này ở vị trí ortho với nhau trên vòng benzen.

\section{Bảng 1}

Số liệu phổ ${ }^{13} \mathrm{C}-\mathrm{NMR}$ và ${ }^{1} \mathrm{H}-\mathrm{NMR}\left(500 \mathrm{MHz}, \mathrm{CDCl}_{3}\right)$ của $\mathrm{RO} 1$

\begin{tabular}{|c|c|c|}
\hline Vị trí C & $\delta_{C}(\mathbf{p p m})$ & $\delta_{H}(\mathrm{ppm})[J(\mathrm{~Hz})]$ \\
\hline 1 & 108,7 & $6,74(\mathrm{~s} ; 1 \mathrm{H})$ \\
\hline 2 & 147,4 & \\
\hline 3 & 147,5 & \\
\hline 4 & 111,4 & $6,62(\mathrm{~s} ; 1 \mathrm{H})$ \\
\hline $4 a$ & 126,8 & \\
\hline 5 & 29,1 & $2,61(\mathrm{~m} ; 2 \mathrm{H})$ \\
\hline 6 & 51,5 & $3,11(\mathrm{~m} ; 2 \mathrm{H})$ \\
\hline 7 & & \\
\hline 8 & 54,0 & $3,52(\mathrm{~m} ; 2 \mathrm{H})$ \\
\hline $8 \mathrm{a}$ & 127,8 & \\
\hline 9 & 145,1 & \\
\hline 10 & 150,3 & \\
\hline 11 & 111,0 & $6,77(\mathrm{~d} ; \mathrm{J}=8,5 \mathrm{~Hz} ; 1 \mathrm{H})$ \\
\hline 12 & 123,8 & $6,86(\mathrm{~d} ; \mathrm{J}=8,5 \mathrm{~Hz} ; 1 \mathrm{H})$ \\
\hline $12 \mathrm{a}$ & 128,6 & \\
\hline 13 & 36,4 & $\begin{array}{c}2,80(\mathrm{~m} ; 1 \mathrm{H}) \\
4,22(\mathrm{~d} ; 1 \mathrm{H})\end{array}$ \\
\hline 14 & 59,3 & $3,55(\mathrm{~m} ; 1 \mathrm{H})$ \\
\hline $14 \mathrm{a}$ & 129,8 & \\
\hline $2-\mathrm{OCH}_{3}$ & 55,86 & $3,88(\mathrm{~s} ; 3 \mathrm{H})$ \\
\hline 3- $\mathrm{OCH}_{3}$ & 56,1 & $3,85(\mathrm{~s} ; 3 \mathrm{H})$ \\
\hline 9- $\mathrm{OCH}_{3}$ & 60,2 & $3,86(\mathrm{~s} ; 3 \mathrm{H})$ \\
\hline $10-\mathrm{OCH}_{3}$ & 55,89 & $3,84(\mathrm{~s} ; 3 \mathrm{H})$ \\
\hline
\end{tabular}

Nguồn: Kết quả phân tích dữ liệu của nhóm nghiên cứu

Dựa vào kết quả trên phổ ${ }^{13} \mathrm{C}-\mathrm{NMR}$ cho thấy hợp chất RO1 thu nhận được có 21 carbon. Phổ ${ }^{13} \mathrm{C}-\mathrm{NMR}$ cho các mũi ở các giá trị 55,$86 ; 56,1 ; 60,2$ và 55,89ppm là các carbon của nhóm $-\mathrm{OCH} 3$ gắn ở $\mathrm{C}_{2}, \mathrm{C}_{3}, \mathrm{C}_{9}$ và $\mathrm{C}_{10}$.

Ngoài ra phổ ${ }^{13} \mathrm{C}-\mathrm{NMR}$ có các mũi của nhóm methylene ở 29,1; 51,5; 54,0 và 36,4ppm của các carbon $\mathrm{C}_{5}, \mathrm{C}_{6}, \mathrm{C}_{8}, \mathrm{C}_{13}$.

Từ phân tích các số liệu phổ của hợp chất RO1 nêu trên, kết hợp so sánh với công bố của Blanchfield và cộng sự (2003), hợp chất RO1 được xác định là rotudin (Hình 5).

Kết quả sắc ký bản mỏng của họ̣p chất rotudin thu nhận được và một số mẫu thuốc trên thị trường 


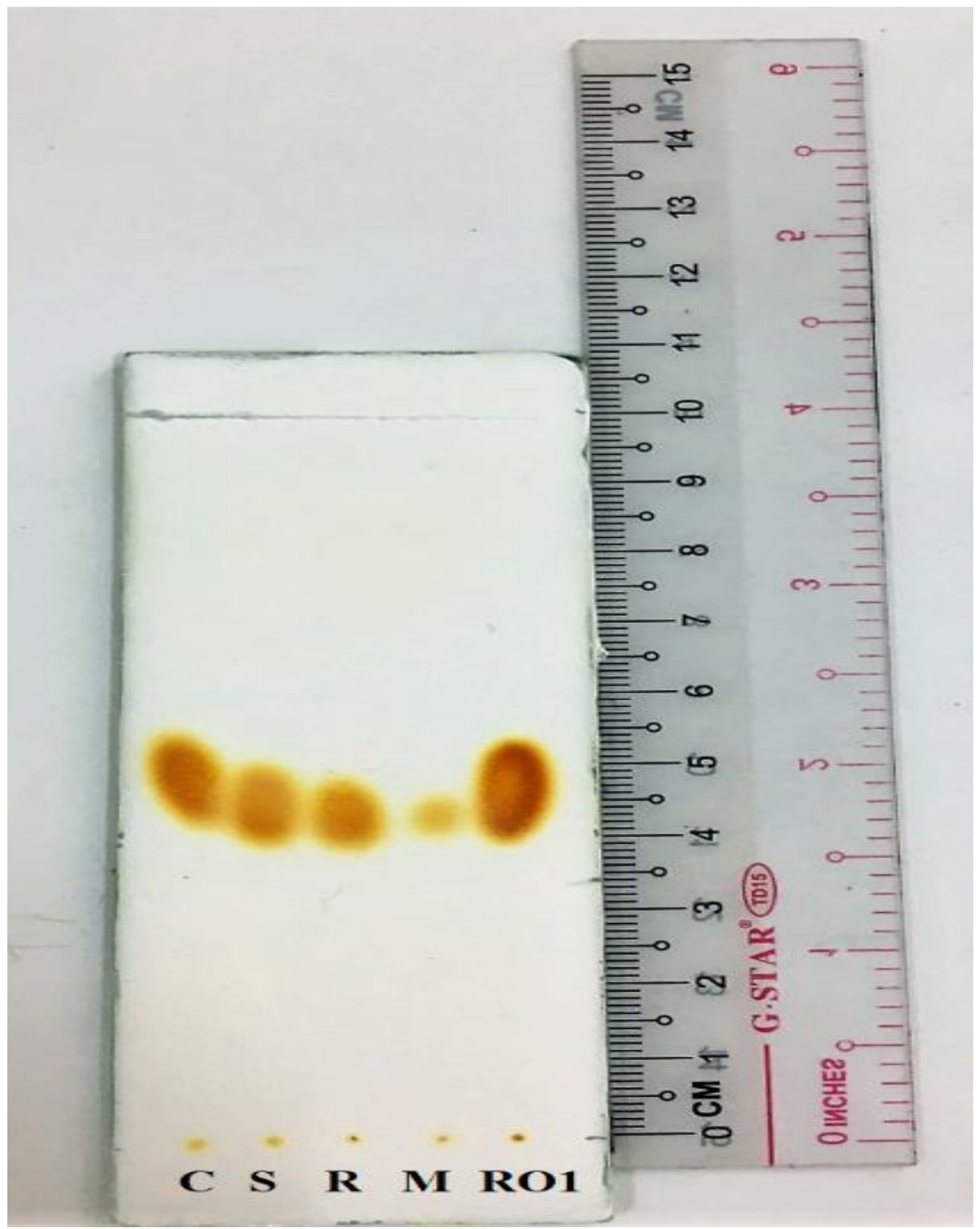

Hình 6. Kết quả sắc ký bản mỏng giữa rotudin và một số loại thuốc Ghi chú: C- rotudin chuẩn, S- thuốc Stilux 60 mg, R- thuốc Rotunda 30 mg, M-thuốc Mimosa, RO1 - rotudin thu được 


\section{Kết luận}

Bột bình vôi ngâm chiết trong dung dịch $\mathrm{H}_{2} \mathrm{SO}_{4} 1 \%$ với tỉ lệ rắn lỏng $1 / 6$ cho hiệu suất chiết alkaloid đạt $0,35 \%$. Từ hỗn hợp alkaloid thô đã cô lập được rotudin đạt độ tinh khiết $98 \%$, cấu trúc hóa học được khẳng định dựa trên các kết quả phổ NMR và MS.

\section{Tài liệu tham khảo}

Blanchfield, J. T., Sands, D. P. A., Kennard, C. H. L., Byriel, K. A., \& Kitching, W. (2003). Characterisation of alkaloids from some Australian Stephania (Menispermaceae) species. Phytochemistry, 63, 711-720.

Bộ Y tế. (2009). Dươc điển Việt Nam IV [Vietnamese pharmacopoeia IV]. Hanoi, Vietnam: Nhà xuất bản Y học.

Do, B. H. (2004). Cây thuốc và động vật làm thuốc ở Việt Nam [Medicinal plants and animals for medicine in Vietnam]. Hanoi, Vietnam: Nhà xuất bản Khoa học và Kỹ thuật.

Do, L. T. (2004). Nhũng cây thuốc và vị thuốc Việt Nam [Vietnamese medicinal plants and herbs]. Hanoi, Vietnam: Nhà xuất bản Y học.

Hung, T. M., Dang, N. H., Kim, J. C., Jang, H., Ryoo, S., Lee, J. H., ... Min, B. S. (2010). Alkaloids from roots of Stephania rotunda and their cholinesterase inhibitory activity. Planta Medica, 76, 1762-1764.

Le, H. M., Ngo, P. T., Nguyen, D. V., Tran, T. V., Nguyen, S. C., Vu, T. D., ... Do, T. T. (2014). Xây dựng phương pháp định lượng rotundin trong củ bình vôi tươi bằng sắc ký lớp mỏng kết hợp đo mật độ quang (TLC-scanning). Tạp chí Dược liệu, 19(6), 375-380.

Semwal, D. K., Badoni, R., Semwal, R., Kothiyal, S. K., Singh, G. J. P., \& Rawat, U. (2010). The genus Stephania (Menispermaceae): Chemical and pharmacological perspectives. Journal of Ethnopharmacology, 132, 369-383.

Thuy, T. T., Franke, K., Porzel, A., Wessjohann, L., \& Sung, T. V. (2006). Quaternary protoberberine alkaloids from Stephania rotunda Lour. Journal of Chemistry, 44(2), 259264. 